\title{
Aerosols: A sustainable route to functional materials
}

\author{
Michael J. Powell and Claire J. Carmalt* \\ Department of Chemistry, University College London, 20 Gordon Street, London, WC1H 0AJ, UK.
}

\section{*c.j.carmalt@ucl.ac.uk}

\begin{abstract}
Sustainability is an increasingly important topic in the design and manufacture of materials, with the need to reduce the environmental impact of producing materials being of paramount significance. A competing interest to this is the ability to produce functional materials in large volumes from a fast, on-line process, which can be integrated easily into existing industrial setups. Herein, we present aerosol assisted chemical vapour deposition (AACVD) routes to advanced functional materials. We will show that by careful design of precursors and manipulation of deposition conditions, it is possible to achieve high sustainability whilst maintaining fast growth rates and large scale production of thin film functional materials.
\end{abstract}

Keywords: Aerosol assisted chemical vapour deposition; sustainability; advanced materials

\section{Introduction}

Thin film functional materials are a vital component of a vast array of technologies including; photocatalysts, batteries, flat-screen displays, solar cells, phone cameras, computing devices and light emitting diodes. ${ }^{[1]}$ For the purpose of this article, we define a functional material as one which has a specific application, such as catalytic, hydrophilic/phobic, electrically conductive, magnetic etc. Thin film technologies are likely to become more prevalent in new and existing technologies as device sizes become smaller and more highly integrated. ${ }^{[2]}$ As such, the ability to reliably deposit thin films, with precise control over thickness, properties and functionality, is imperative for large-scale industrial production. There are, however, competing factors at play with current and potential processes to synthesise thin film materials; these include the need to sustainably form functional materials as well as balance this against the economic price and rate of production. In other words, it is no good to have a process that has no harmful by-products and $100 \%$ efficiency if the deposition rate is so low that it is not economically viable as this will not be adopted by industry.

For a deposition technology to be widely adopted by industry it needs to fulfil several of, or ideally all of, the following criteria: 1) high growth rates, 2) reliable control over stoichiometry, 3) ease of control over thickness, 4) ability to change properties for different applications, 5) high efficiency, 6) flexibility to coat a variety of substrates, 7) ability to deposit a wide range of materials, 8) non-toxic precursors and by-products and 9) high sustainability. For future functional materials and applications, these criteria are only likely to become more important especially points 8 and $9 .{ }^{[3]}$

Chemical vapour deposition (CVD) is a widely used industrial technique to deposit thin films of materials with high growth rates and coverage. Traditional CVD methods, such as atmospheric pressure (AP)CVD, rely on volatile precursors to react to form the thin film. ${ }^{[4]}$ This type of technology can satisfy points 1-7 above, however due to the nature of the precursors, toxicity and sustainability are issues. Due to the requirement that the precursors must be volatile, which for metal containing 
precursors typically means that metal halides are the main suitable precursors, it is difficult to improve the sustainability of APCVD processes. For this reason, other thin film deposition techniques have been researched to find alternative routes with higher sustainability. ${ }^{[5]}$

The process we will concentrate on for this concept article will be aerosol assisted (AA)CVD. In an AACVD process, the precursors are delivered to the reactor via the nebulisation of a solution. ${ }^{[6]}$ Therefore, the need for volatile precursors is removed as the precursor(s) is delivered to the reactor in a mist, which contains droplets of solvent with the precursor dissolved in. As volatility is no longer a requirement, a much larger range of precursors are available as potential candidates for CVD. ${ }^{[4]}$ The precursors can also be designed to reduce the environmental impact of the reactions conducted to deposit the thin films.

As well as being able to increase the sustainability of CVD processes, being able to design precursors can also enable the synthesis of complex ternary and quaternary phases and provide precise control over the incorporation of dopants into materials. This allows the deposition of advanced materials, with the ability to optimise the properties for specific applications.

In this concept article we will outline the current research in sustainable routes for the production of advanced functional materials. We will also discuss the current challenges and future direction of this field of materials chemistry.

\section{Aerosol Routes to Sustainable Manufacture of Materials}

\subsection{Aerosol Assisted Chemical Vapour Deposition (AACVD) Mechanism}

In any AACVD process there are several fundamental steps that have to occur to result in the formation of the desired material, as follows:

1) The precursor solution must be atomised, which is most typically achieved by using an ultrasonic humidifier to cause the formation of a 'mist' where droplets of the solution are formed. The precursor mist can also be formed by collision atomisers.

2) The precursor mist must then be carried to the reactor by a carrier gas. This is where AACVD is differentiated from spray pyrolysis, since the longer residence time of the precursor mist means that there is more possibility for reactions to occur prior to absorption onto the substrate surface. In a typical laboratory experiment, the mist will be carried anywhere from $10 \mathrm{~cm}$ to 1 metre prior to deposition. This means that in an AACVD process, the substrate is never wetted- therefore AACVD is a true CVD process and so bulk textures and film morphologies are unaffected by the hydrodynamics associated with the vaporization of the solvent at the hot substrate surface.

3) The precursor mist must be passed over a heated substrate, where the solvent evaporates and the precursor(s) can then react to form the desired material. Waste products are then carried away to an exhaust.

Once the solvent has evaporated, the mechanism for reaction is similar to typical CVD reactions. The accepted mechanism for AACVD processes is shown in Figure 1. There are 5 steps to an AACVD process, ${ }^{[7]}$ which are: 1 ) gas phase reactions occurring to allow mixing of precursors (if there are 2 or more precursors in the solution), 2) precursors pass through boundary layer to be absorbed onto the 
surface of the substrate, 3) precursors nucleate and react, 4) desorption of waste products occurs and 5) more precursors molecules are absorbed on the surface and react resulting in film growth.

AACVD can be used to deposit numerous types of thin films, in this concept article we will focus on binary metal oxides/sulfides, ternary and quaternary oxides.

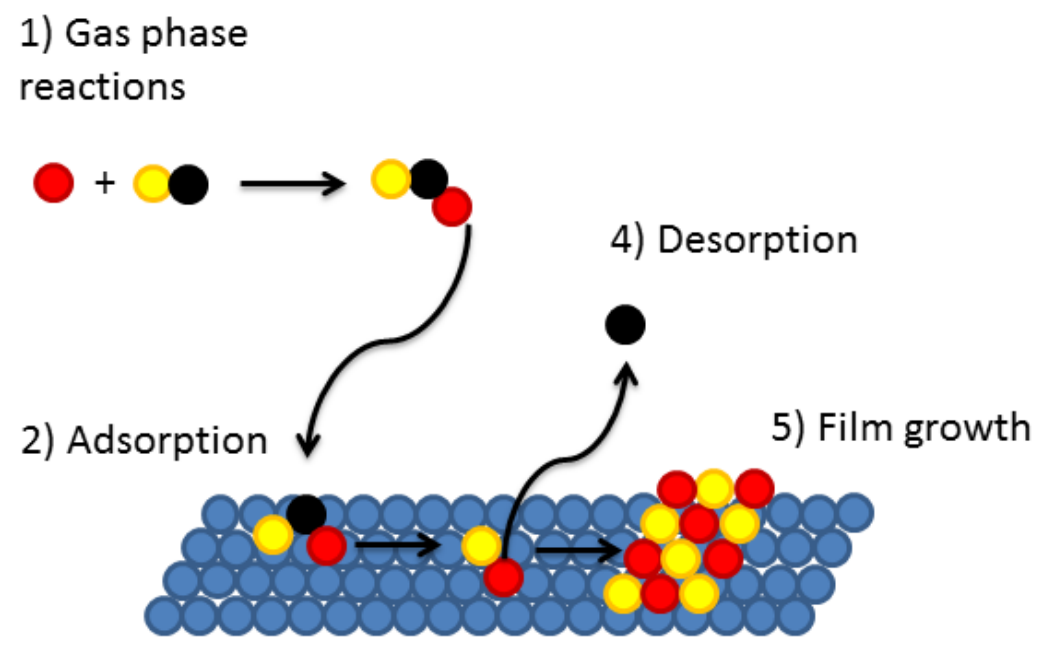

3) Nucleation

Figure 1: Mechanism for AACVD processes: 1) Gas phase reactions can occur to allow mixing of precursors, 2) Precursors pass through boundary layer to be absorbed onto the surface of the substrate, 3) Precursors nucleate and react, 4) Desorption of waste products occurs and $\mathbf{5}$ ) Precursors continue to react resulting in film growth.

\subsection{AACVD experimental set-up and equipment}

In a typical laboratory scale AACVD set-up, the rig consists of a reactor, to heat the substrate to the desired temperature, piping to allow the carrier gas and precursor 'mist' to be flowed through the reactor and a method for producing the aerosol from the precursor solution, Figure 2.

In a typical reaction, a substrate will be loaded into the reaction chamber, suspended above this is a top plate to ensure laminar flow and reduce turbulence within the reaction chamber, ensuring uniform film growth. The substrate will then be heated to the desired temperature for deposition of the material to occur. Once the reactor is at temperature, the precursor will be atomised to create an aerosol. This aerosol will then be passed over the heated substrate by means of a carrier gas. Depositions typically continue until all the precursor solution has been atomised and passed over the substrate. For lab-scale reactions, the precursor solution will generally be between $20-40 \mathrm{~mL}$ in volume and take between 30-60 mins to be completely atomised. After the deposition is complete, the reactor will be cooled normally under a flow of carrier gas.

There are two primary methods for generating the precursor 'mist'. These are by use of a piezoelectric ultrasonic humidifier or a collision type atomiser. Of the two, the ultrasonic method is most commonly used to atomise precursor solutions for AACVD reactions.

In the case of the ultrasonic humidifier, the solution will be placed in a bubbler, which will be then suspended in water. A piezoelectric element will then generate ultrasonic pulses. As these pulses pass through the solution, they cause the solvent and precursor molecules to move, however, the 
frequency of the ultrasound is faster than the ability of the solvent/precursor molecules to respond. This creates voids within the solution, when these voids collapse they generate droplets which can then be carried away from the solution by the carrier gas.

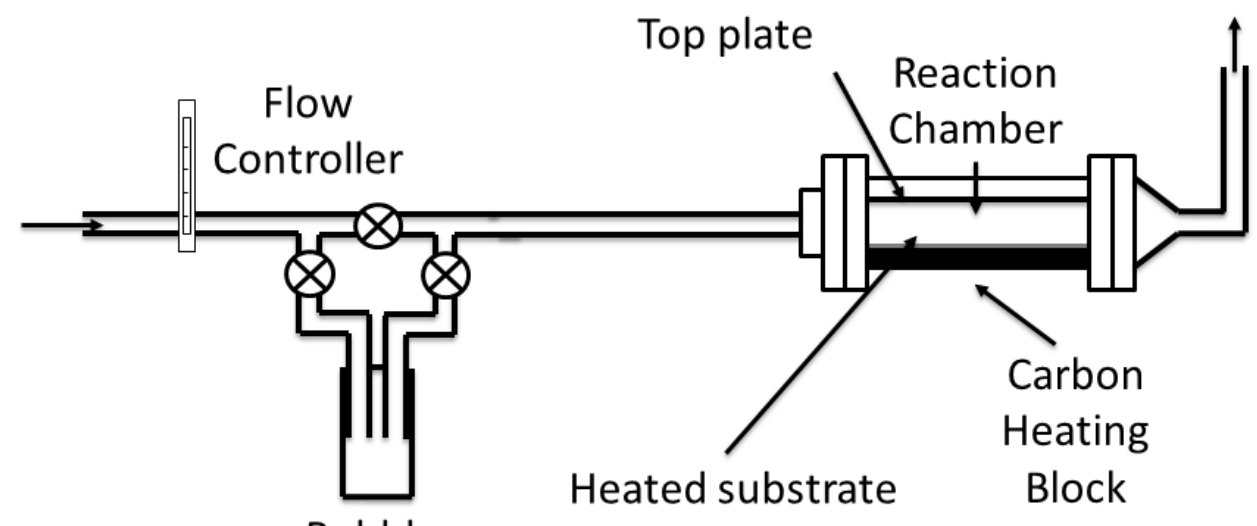

Bubbler

Figure 2: Typical laboratory set-up for aerosol assisted chemical vapour deposition reactions. The substrate is heated to the desired temperature before the precursor 'mist' is passed over via a carrier gas. This results in chemical reactions occurring on the surface of the heated substrate resulting in the formation of a film.

For the collision atomisers, a high pressure gas stream is used to generate the precursor 'mist'. In this design, the carrier gas is passed through a small aperture, which generates the pressure required. The carrier gas then draws the solution from a reservoir toward the atomisation chamber, through capillary action. When the solution reaches the atomisation chamber it is obliterated by the high pressure gas stream, this causes the formation of droplets which can then be carried towards the reaction chamber by the carrier gas.

The differences on the surface morphology and texture of the thin films deposited by APCVD, ultrasonic AACVD and collision AACVD are shown in Figure 3. By varying the way that the aerosol is produced, primarily by the size of the droplet formed in the process, it is possible to develop highly textured films. This enables the surface area of the film to be manipulated, enabling the surface area to be tailored for a particular functional property. For instance, catalytic materials can be improved by increasing the surface area of the material. Textured films can also lead to higher scattering of light, which is beneficial for increasing the efficiency of certain solar cell devices. 


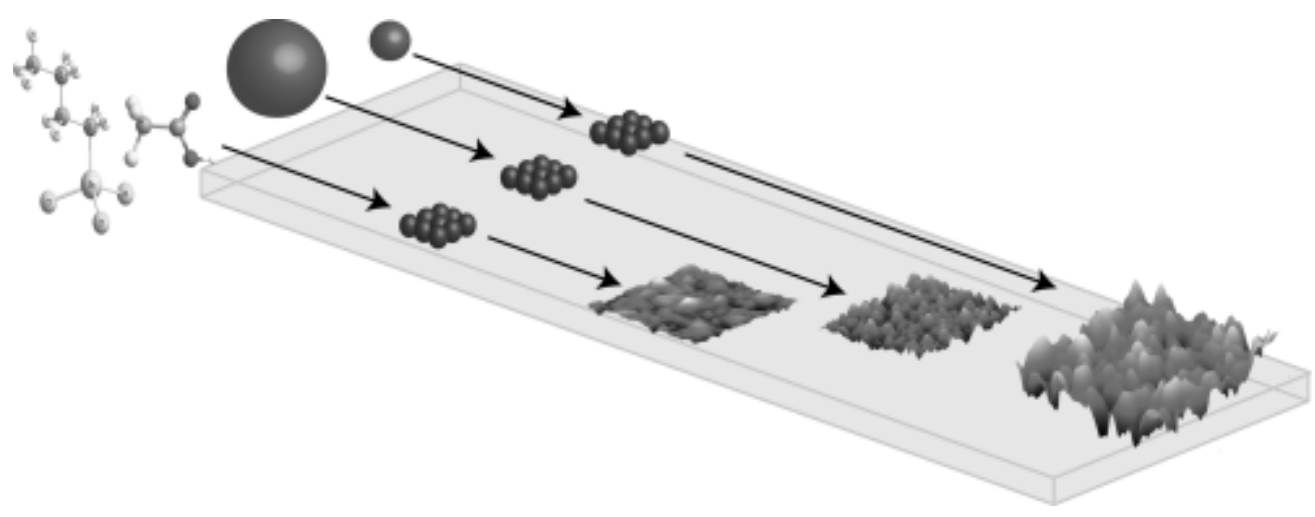

Figure 3: Schematic diagram showing the difference between APCVD (left), ultrasonic AACVD (centre) and collision AACVD (right) on the morphology and texture of deposited thin film surfaces. Reprinted with permission from Chemistry a European Journal. ${ }^{[8]}$ Copyright 2011 Wiley-VCH.

\subsection{Deposition of binary metal oxide and doped metal oxide materials}

Binary metal oxides, such as $\mathrm{TiO}_{2}, \mathrm{WO}_{3}$ and $\mathrm{ZnO}$, are commonly deposited for functional material applications. With applications ranging from self-cleaning surfaces, ${ }^{[9]}$ electrochromic materials, ${ }^{[10]}$ transparent conducting oxides ${ }^{[11]}$ and abrasion resistant coatings, ${ }^{[12]}$ there are many $100 \mathrm{~s}$ of $\mathrm{km}$ of material deposited each year. Reducing the environmental impact of producing such materials would make a significant contribution to achieving greater sustainability.

AACVD can contribute to this change by altering the waste products formed from these processes. For the production of $\mathrm{TiO}_{2}, \mathrm{WO}_{3}$ and $\mathrm{ZnO}$, the traditional metal halide precursors can be exchanged for organometallic precursors, such as $\mathrm{Ti}(\mathrm{IV})$ ethoxide, $\mathrm{W}(\mathrm{VI})$ ethoxide and $\mathrm{Zn}$ (II) acetylacetonate, thus eliminating the production of $\mathrm{HCl} / \mathrm{Br} / \mathrm{I}$ as waste products. This in turn means that there is no risk of these waste products being released and the cost of production can be decreased as well as the need to introduce energy intensive scrubbing methods to the exhaust gases.

The use of metal alkoxides, amidates and derivatives as precursors has been successfully demonstrated for the synthesis of metal oxide thin films, such as $\mathrm{TiO}_{2},{ }^{[13]} \mathrm{WO}_{3},{ }^{[14]} \mathrm{VO}_{2},{ }^{[15]} \mathrm{ZnO},{ }^{[16]}$ $\mathrm{ZrO}_{2}{ }^{[17]}$ and $\ln _{2} \mathrm{O}_{3} \cdot{ }^{[18]}$ As these metal precursors are soluble in a large range of solvents, there is a greater ability to control the incorporation of dopants. This is due to the fact that the ability to control the concentration of a dopant in solution is much greater than in the gas phase. Additionally, there are a wider variety of dopants that can be incorporated as the solubility, and not the necessity of ease of vaporisation, of the dopant is the controlling factor. This means that the precursors incorporated can be tailored to ensure that the breakdown products are non-toxic and ecologically benign, reducing the energy required to process exhaust gases and waste products, thus reducing the environmental impact of producing the desired material.

The deposition of $\mathrm{Ga}_{x} \mathrm{In}_{2-x} \mathrm{O}_{3}$ thin films has been achieved at $450{ }^{\circ} \mathrm{C}$ via AACVD using $\mathrm{GaMe}_{3}$, InMe and $\mathrm{HOCH}_{2} \mathrm{CH}_{2} \mathrm{OMe}$ in toluene. ${ }^{[19]}$ Dimethyalkoxometallanes, of the type $\left[\mathrm{Me}_{2} \mathrm{M}\left(\mathrm{OCH}_{2} \mathrm{CH}_{2} \mathrm{OMe}\right)\right]_{2}(\mathrm{M}$ $=\mathrm{Ga}, \mathrm{In}$ ) were generated in situ in the AACVD bubbler, and hence a facile method for deposition of these films resulted since it bypassed the need to synthesize, isolate and purify a single-source metal alkoxide precursor and no oxygen carrier gas was required. By varying the concentration of the Ga and In precursors, optimisation of the films properties could be easily achieved. These films 
displayed excellent transparency and electrical conductivity, meaning that they would be suitable for transparent conducting oxide applications. ${ }^{[1]}$

The versatility of AACVD methods has also been shown by the deposition of $\mathrm{WO}_{3}$ and Ti-doped $\mathrm{WO}_{3}$ thin films from $\left[\mathrm{W}(\mathrm{OPh})_{6}\right]$ and $\left[\mathrm{Ti}\left(\mathrm{O}^{\mathrm{i}} \mathrm{Pr}\right)_{4}\right]$ in acetone. ${ }^{[20]}$ Due to the use of a solution-based method, $\mathrm{Ti}$ incorporation could be easily modified to optimise the photochromic response of the $\mathrm{WO}_{3}$. Photochromic materials, such as $\mathrm{WO}_{3}$, have a colour change induced by the action of light. This gives potential applications such as optical data storage, molecular switches and solar control coatings. ${ }^{[21]}$ These types of materials when deposited via traditional CVD techniques require the metal halides $\mathrm{WCl}_{6}$ and $\mathrm{TiCl}_{4}$, therefore being able to deposit these films using precursors that do not contain chlorine is very desirable.

Even if the precursor(s) are not all soluble in the same solvent this is not a barrier to incorporation when using AACVD; as two or more precursor 'mists' can be combined within the reactor to achieve the desired material. An example of this is the co-doping of $\mathrm{F}$ and $\mathrm{Al}$ into $\mathrm{ZnO}$ thin films. ${ }^{[22]}$ In this study, the $\mathrm{F}, \mathrm{Al}$ and $\mathrm{Zn}$ precursors were ammonium fluoride, trimethyl aluminium and diethyl zinc respectively. The aluminium and zinc precursors were soluble in toluene, whereas the fluorine precursor was most soluble in methanol. By combining the two aerosols within the reactor, $\mathrm{F}$ and $\mathrm{Al}$ co-doped $\mathrm{ZnO}$ thin films were successfully synthesised. These films displayed excellent electrical conductivity and high visible light transmission, making the material an ideal candidate for transparent conducting oxide applications.

As the precursor does not need to be volatile for AACVD, precursors can be designed to have specific decomposition routes, which allows for the sustainability of the process to be increased. One such precursor type, which has been used to successfully form a variety of binary metal oxides, is the use of $\beta$-diketonate ligands. We have been able to demonstrate this for the deposition of $\mathrm{ZnO}^{[23]}$ $\mathrm{In}_{2} \mathrm{O}_{3}{ }^{[18]}$ and $\mathrm{VO}_{2}{ }^{[24]}$ thin films. $\beta$-diketonate ligands have also been used to deposit $\mathrm{WO}_{3}{ }^{[25]}$ and $\mathrm{CuO}^{\left[{ }^{[26]}\right.}$ There are also a wide variety of $\beta$-diketonate ligands known for metals including: $\mathrm{Ti}^{\left[{ }^{[27]}\right.} \mathrm{Hf}^{[27]}$ $\mathrm{Ta}^{[28]}{ }^{[2 r},{ }^{[29]} \mathrm{Ca},{ }^{[30]} \mathrm{Mg},{ }^{[31]}$ and $\mathrm{Ba},{ }^{[32]}$ therefore a wide range of metal oxide materials are accessible via such precursors.

The reason why ligands, such as $\beta$-diketonates, are favoured for AACVD is due to the facile decomposition pathway. In a $\beta$-diketonate ligand, shown in Figure 4, there are hydrogen atoms in the position beta to the diketone chelate ring, which can activate thermal decomposition. ${ }^{[33]}$ These hydrogen atoms can undergo $\beta$-elimination, which means that there is a clean decomposition pathway, with little carbon contamination of the product. The ligand can also be altered so that the decomposition occurs at lower temperatures, which can help to form crystalline products at reduced temperatures. This can be achieved by altering the R-groups allowing the reaction to proceed at lower activation energies. These two factors combined can reduce the energy required to produce crystalline thin film materials, as there are cleaner reaction pathways at lower temperatures. 


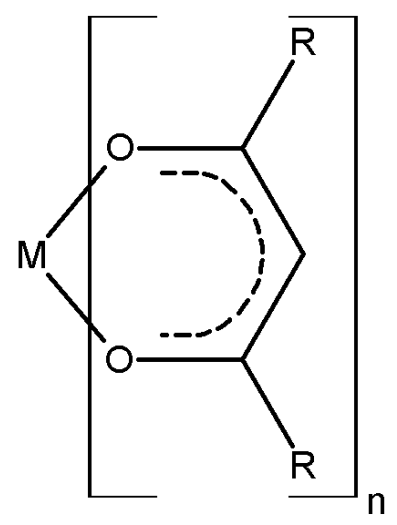

Figure 4: Chemical structure of $\beta$-diketonate ligand. By altering the $\mathrm{R}$ groups, it is possible to tailor the solubility and reactivity of the precursor.

A proposed mechanism for the decomposition pathway of $\beta$-diketonate ligands is shown in Figure 5 . By altering the R-groups, it would be possible to lower the activation energy of this decomposition.<smiles>[M]OC(=Cc1cc([R])cc(C([R])([R])[R])c1)OC([R])=CC1OC1[R]</smiles>

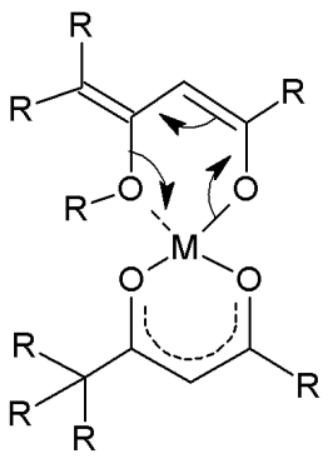<smiles>[R]OC(=CC([R])=O)C([R])([R])[R]</smiles><smiles>[R]C(=O)C=C=C([R])[R]</smiles><smiles>[R]C=C([R])C=C([M]O[M]O[R])C([R])([R])[R]</smiles><smiles>COI</smiles><smiles>[R][R]1=C(OC(=CC([R])=O)C([R])([R])[R])O1</smiles>

Figure 5: Possible decomposition pathway for $\beta$-diketonate ligand to yield metal oxide. $M$ stands for any metal centre. $R=$ $\mathrm{Me}, \mathrm{H}$. Reaction scheme adapted from Gordon et al. ${ }^{[33]}$ 
The choice of R-group can also infer stability onto particular oxidation states of the metal centre. This means that AACVD techniques can be used to access metastable phases. Wang et al. have demonstrated that the precursors zirconium acetylacetonate and yttrium acetylacetonate can be used to deposit yttria-stabilized zirconia at temperatures as low as $500{ }^{\circ} \mathrm{C}$ (cf. typical deposition temperatures of between $\left.800-1100^{\circ} \mathrm{C}\right) .{ }^{[34]}$

The metastable phase $\mathrm{Sn}(\mathrm{II}) \mathrm{O}$ has also been synthesised via AACVD methods. ${ }^{[35]} \mathrm{SnO}$ is a promising $p$-type material, $p$-type materials are essential for solar cells and flat screen displays, where $p$ - $n$ junctions are essential to the functioning of the material. ${ }^{[36]} P$-type materials, however, are much less common than $n$-type for binary metal oxides, therefore being able to sustainably synthesise such materials would be highly advantageous. SnO is difficult to synthesise due to the ease of disproportionation of $\mathrm{Sn}$ at elevated temperatures. By synthesising a single-source tin precursor, $\mathrm{Sn}(\mathrm{II})$ bis(ureide), SnO thin films could be successfully deposited at temperatures as low as $250{ }^{\circ} \mathrm{C}$, preventing the disproportionation of the $\mathrm{Sn}$ centres. As the single-source precursor did not contain any halogens, the process is also highly sustainable.

SnO thin films have also been deposited using $\left[\mathrm{Sn}_{6}(\mathrm{O})_{4}\left(\mathrm{OSiMe}_{3}\right)_{4}\right]$ and $\left[\left\{\mathrm{Sn}\left(\mathrm{OSiMe}_{3}\right)_{2}\right\}_{2}\right]$ as the $\mathrm{Sn}$ ligands. ${ }^{[37]}$ In these reactions, it was found that the temperature of deposition was key to achieving $\mathrm{SnO}$ thin films. At a deposition temperature of $450^{\circ} \mathrm{C}, \mathrm{SnO}$ thin films were achieved from both of the precursors. Above this deposition temperature, however, metallic tin films were found to be deposited instead.

AACVD methods have also been able to synthesise phase pure $\alpha-\mathrm{Fe}_{2} \mathrm{O}_{3}$ thin films on F-doped $\mathrm{SnO}_{2}$ substrates. ${ }^{[38]}$ In this work, the hexanuclear iron precursor $\left[\mathrm{Fe}_{6}(\mathrm{PhCOO})_{10}(\mathrm{acac})_{2}(\mathrm{O})_{2}(\mathrm{OH})_{2}\right]_{3} \cdot 3 \mathrm{C}_{7} \mathrm{H}_{8}$ was synthesised and shown that at a deposition temperature of $475{ }^{\circ} \mathrm{C}$, pure phase $\alpha-\mathrm{Fe}_{2} \mathrm{O}_{3}$ thin films could be synthesised. Achieving pure phase iron oxides is complicated due to the intricate phase diagram and solid-solution like behaviour of these oxides. $\alpha-\mathrm{Fe}_{2} \mathrm{O}_{3}$ when combined in a heterojunction with F-doped $\mathrm{SnO}_{2}$ is a promising material for water splitting applications. By being able to deposit these films from a single-precursor route, at relatively low temperatures and without the need for halogens in the precursor, these types of material can be produced sustainably.

A further advantage to AACVD is the fact that the process relies on a solvent to transport the precursor to the reaction chamber. Therefore, the choice of solvent can have a large impact on the structure and phase of the material deposited. Edusi et al. have shown that by changing the solvent mix to include differing proportions of methanol and ethanol, it is possible to deposit rutile $\mathrm{TiO}_{2}$ at temperatures as low as $500{ }^{\circ} \mathrm{C}$ ( $c f$. APCVD where rutile only forms above $750{ }^{\circ} \mathrm{C}$ ). ${ }^{[39]}$ By being able to reduce the temperature required to form a particular crystalline phase, this can significantly lower the cost of production and reduce the energy required to synthesise such films.

\subsection{Deposition of binary metal sulfide materials}

As well as wanting to deposit metal oxides as functional materials, another widely researched area is the deposition of sulfide materials. Materials such as $\mathrm{Cu}_{2} \mathrm{~S}, \mathrm{Ni}_{3} \mathrm{~S}_{2}, \mathrm{MoS}_{2}$ and $\mathrm{CdS}$ are commonly synthesised metal sulfide thin films. ${ }^{[40]}$ Such materials are used as absorbers in photovoltaics and for battery cathodes/anodes. As with the binary metal oxide materials discussed above, it is desirable to have routes that have greater sustainability and a larger range of precursors to synthesise these materials. Typical processes to deposit thin films of metal sulfides include; atomic layer deposition, 
molecular beam epitaxy, APCVD and electrodeposition. All of these processes suffer from either difficulty in scaling, poor sustainability in terms of precursors/waste products and/or energy intensive (high temperature, elevated pressure etc.) reaction conditions. This means that any process that can reduce these limitations has excellent potential for producing these materials.

An important consideration when developing precursors for sulfide materials is the presence of oxygen, the $\mathrm{S}=\mathrm{O}$ bond is thermodynamically favoured and has a large bond energy (ca. $520 \mathrm{~kJ} \mathrm{~mol}^{-1}$ ) and so will preferentially form if there is oxygen present. Therefore precursors, such as dithiocarbamates, as shown in Figure 6, are commonly used to synthesise metal sulfide thin films, since these compounds are stable due to their bidentate coordination. ${ }^{[41]}$ Then by careful manipulation of the deposition conditions, oxygen-free products can be successfully deposited.

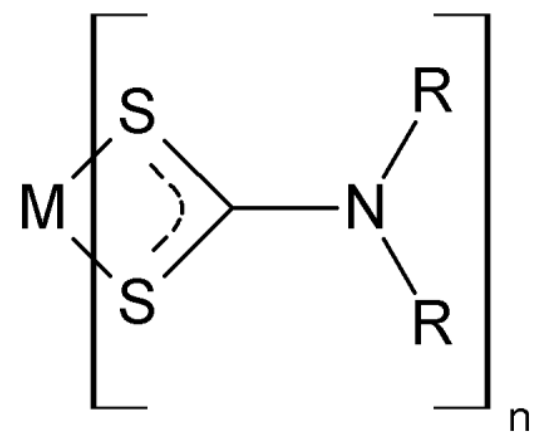

Figure 6: Chemical structure of dithiocarbamate ligand. As with $\beta$-diketonate ligands, by altering the $R$ groups it is possible to tailor the solubility and reactivity of the precursor.

A proposed decomposition pathway is shown in Figure 7. As shown, there are a variety of routes via which dithiocarbamate ligands can decompose, however, a key step is the removal of the nitrogen containing groups. 
<smiles>[R]NC1=[SH][N+]2(S1)S[N+]1(S[S+]1)S2</smiles>

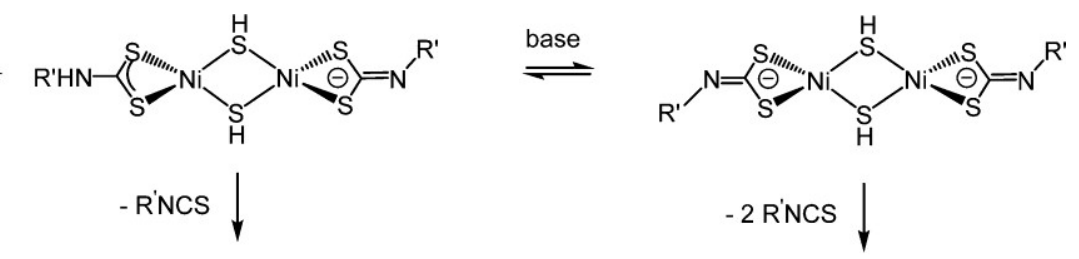

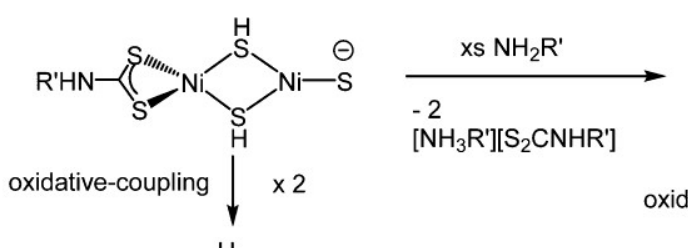

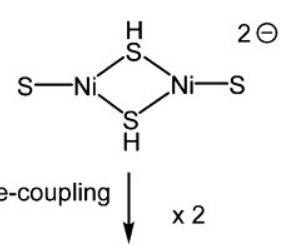

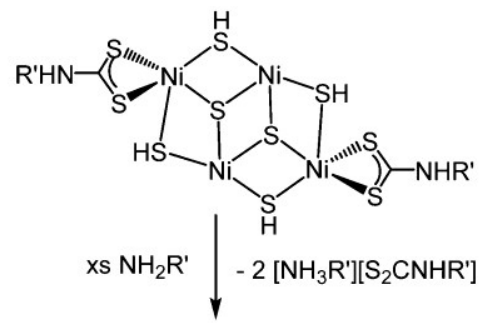

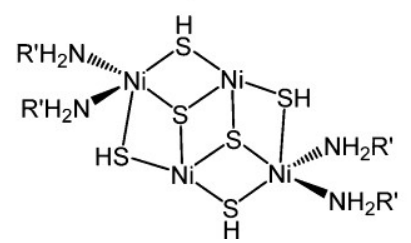

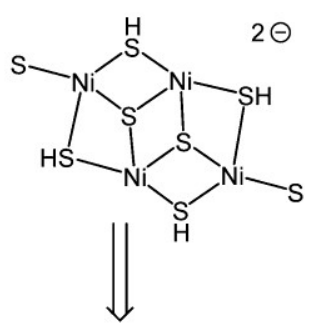

$\mathrm{Ni}_{3} \mathrm{~S}_{4}$ nanoparticles

Figure 7: Proposed decomposition pathway for the formation of $\mathrm{Ni}_{3} \mathrm{~S}_{4}$ from Ni dithiocarbamate precursor. Reprinted with permission from Chemistry of Materials. ${ }^{[42]}$ Copyright 2014 American Chemical Society.

A large range of metal sulfide materials are accessible by using dithiocarbamate ligands in AACVD reactions. ${ }^{[43]}$ This has included the synthesis of SnS thin films from single precursor diorganotin dithiocarbamate routes. ${ }^{[44]}$ Tin sulfides exist in a variety of stoichiometries, so being able to deposit phase pure materials is challenging. In this study, it was shown that the deposition of SnS was achievable by a single step decomposition of $\left[\mathrm{Sn}\left(\mathrm{C}_{4} \mathrm{H}_{9}\right)_{2}\left(\mathrm{~S}_{2} \mathrm{CN}\left(\mathrm{RR}^{\prime}\right)_{2}\right)_{2}\right]$ when $\mathrm{R}$ and $\mathrm{R}^{\prime}$ were either both ethyl or both butyl groups. The decomposition temperature of these precursors was found to be between $210-300{ }^{\circ} \mathrm{C}$, therefore making this an ideal single-source precursor for AACVD methods, where typical deposition temperatures are greater than $400^{\circ} \mathrm{C}$.

Another metal sulfide thin film that has been successfully deposited via AACVD is $\mathrm{MoS}_{2}{ }^{[45]}$ This is a material that displays excellent lubricity and so is commonly used as a lubricant in industrial applications where high temperatures and pressures are typical, where traditional organic lubricants would degrade. In this study $\left[\mathrm{Mo}\left(\mathrm{S}_{2} \mathrm{CN}\left(\mathrm{C}_{2} \mathrm{H}_{5}\right)_{2}\right)_{4}\right]$ was used to deposit $\mathrm{MoS}_{2}$ thin films. Doping of the films by $\mathrm{Cr}$, to increase the lubricity, was shown to be easily achieved by addition of $\left[\mathrm{Cr}\left(\mathrm{S}_{2} \mathrm{CN}\left(\mathrm{C}_{2} \mathrm{H}_{5}\right)_{2}\right)_{3}\right]$ to the starting precursor solution.

\subsection{Deposition of composite thin films}

The development of various technologies, including solar cells and flat screen displays, has often required conflicting properties to be present in the materials in the device. This means that single layers of binary metal oxides or sulfides are often unable to deliver the desired properties. Due to this reason composite thin films are often deposited. Here the individual components can be tailored for specific applications and so the overall desired functionality can be achieved. 
As with the previously discussed sections, there is again a large potential for achieving higher sustainability within the synthesis of these sorts of structures. There have been reports on the rapid synthesis, ca. $1 \mathrm{~min}$, of nanocomposite thin films. ${ }^{[46]}$ However, these have involved the use of solvents such as 1-dodecanethiol, which is highly toxic to aquatic life and so not ideal from a sustainable point of view, as the energy and cost required to process the materials and waste are high.

AACVD methods can help to significantly reduce these costs and so help increase the sustainability of producing nanocomposite films. AACVD methods can also be used to either incorporate preformed nanoparticles into thin films, or decompose precursors to form nanoparticle in situ during the deposition of the thin film. ${ }^{[7]}$ Surfactants can be included to help the dispersion of the nanoparticles in the precursor solution, which can lead to higher loadings of nanoparticles in the deposited thin films and more uniform spacing between the nanoparticles. ${ }^{[4]}$

By being able to manipulate the reaction conditions, it is therefore possible to exclude certain solvents and precursors from reactions, which are known to either be harmful or generate unwanted toxic by-products. Such an approach was demonstrated where gold nanoparticles were successfully deposited into $\mathrm{TiO}_{2}$ and $\mathrm{WO}_{3}$ thin films, ${ }^{[47]}$ From a solution of toluene, containing preformed gold colloids, either $\left[\mathrm{Ti}\left(\mathrm{O}^{i} \mathrm{Pr}\right)_{4}\right]$ or $\left[\mathrm{W}\left(\mathrm{O}^{i} \mathrm{Pr}\right)_{6}\right]$ was added. These solutions were then atomised and passed over a heated substrate, at $c a .500{ }^{\circ} \mathrm{C}$, using $\mathrm{N}_{2}$ as the carrier gas. The Au nanoparticles could be clearly seen in the morphology of the deposited films, as shown in Figure8. By varying the concentration of the gold colloids in the starting precursor solution, a variety of Au nanoparticle sizes could be formed within the film. This allowed the colour of the film to be altered. As the Ti and $\mathrm{W}$ precursors and toluene solvent used did not contain halogens, the amount of halogenated waste formed was significantly reduced $c f$. APCVD methods. The Au precursor, however, did contain $\mathrm{Cl}$ and $\mathrm{Br}$, so to further improve the sustainability of the process, alternative methods for producing the $\mathrm{Au}$ nanoparticles would need to be used.

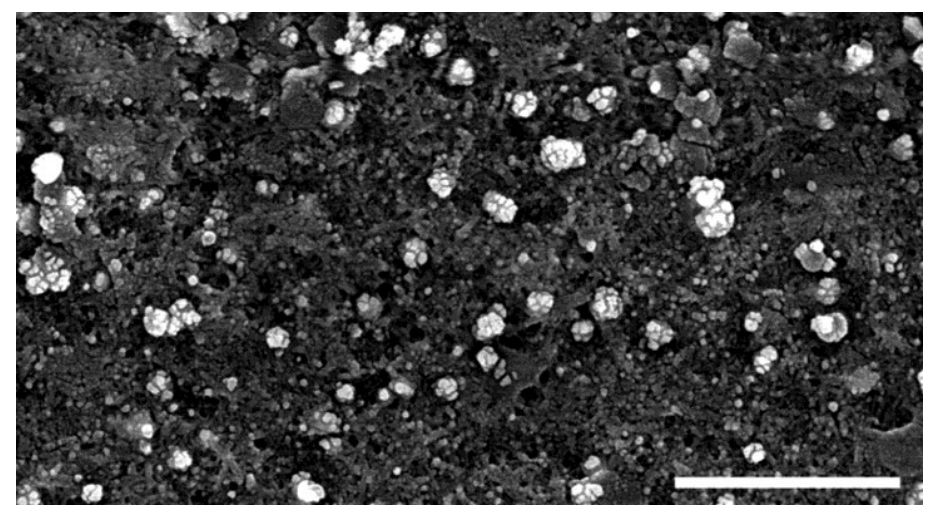

Figure 8: Surface morphology of $\mathrm{Au}$ nanoparticles in $\mathrm{WO}_{3}$ thin film deposited by AACVD. The Au nanoparticles can be clearly seen as bright spherical particles within the darker $\mathrm{WO}_{3}$ matrix. The scale bar measures $1 \mu \mathrm{m}$. Reprinted with permission from Journal of the American Chemical Society. ${ }^{[47]}$ Copyright 2006 American Chemical Society.

Preformed nanoparticles of ceria $\left(\mathrm{CeO}_{2}\right)$ can also be incorporated into thin films of $\mathrm{TiO}_{2}$ via AACVD. ${ }^{[48]}$ This occurred in two steps, with deposition of $\mathrm{TiO}_{2}$ from a solution of $\left[\mathrm{Ti}\left(\mathrm{O}^{i} \mathrm{Pr}\right)_{4}\right]$ in toluene followed by a layer of $\mathrm{CeO}_{2}$ nanoparticles being deposited on top via the atomisation of $\mathrm{CeO}_{2}$ nanoparticles suspended in water. This process was then repeated to build up the film. The nanocomposite films were shown to have enhanced photocatalytic properties for the destruction of 
stearic acid. This elucidates that as well as achieving greater sustainability of deposition of metal oxide thin films, AACVD techniques can also be used simultaneously to enhance the functional properties of the deposited thin films. In other words, the reduction in energy and cost of producing the material does not entail a similar reduction in the properties of the synthesised material.

Single molecular precursor routes have also been demonstrated to yield nanocomposite films via AACVD. The precursors of $\left[\mathrm{Cd}_{2}(\mathrm{OAc})_{6}(\mu-\mathrm{O}) \mathrm{Cu}_{4}(\mathrm{dmae})_{4}\right] \cdot \mathrm{H}_{2} \mathrm{O}$ and $\left[\mathrm{Zn}_{2}(\mathrm{OAc})_{6}(\mu-\mathrm{O}) \mathrm{Cu}_{4}(\mathrm{dmae})_{4}\right] \cdot 3 \mathrm{H}_{2} \mathrm{O}$ were synthesised, ${ }^{[49]}$ and after passing over heated substrates (between $450-500{ }^{\circ} \mathrm{C}$ ), composite thin films of $\mathrm{Cu}-\mathrm{CdO}$ and $\mathrm{Cu}-\mathrm{ZnO}$ were deposited. $\mathrm{Cu}-\mathrm{CdO}$ is a ceramic, whilst $\mathrm{Cu}-\mathrm{ZnO}$ has been used as a catalyst for the industrial production of methanol. Having a low temperature route to these materials is thus beneficial, as the energy required to produce the material is reduced.

AACVD can be employed to give films with graded dopant concentrations. This is especially useful as a screening test to establish the ideal concentrations of two or more dopants within a crystal lattice. In such a combinatorial deposition, two or more precursor 'mists' can be combined within the reactor to achieve the desired material. An example of this is the ability to co-dope $\mathrm{TiO}_{2}$ thin films with $\mathrm{N}$ and $\mathrm{Nb}{ }^{[50]}$ As the nitrogen and niobium precursors are being separately flowed into the reactor, a graded composition of $\mathrm{N} / \mathrm{Nb}$ is formed within the deposited thin film. These films were shown to display excellent photocatalytic properties whilst also displaying low resistivity and hence producing a multifunctional material.

\subsection{Deposition of ternary and quaternary metal oxides and sulphides}

Over the last decade there has been an increasing focus on the synthesis of thin films of ternary and quaternary metal oxides/sulphides/selenides. This is due to the interesting chemical and physical properties that are observed in these materials and the potential to further enhance the functional properties of materials for battery, ${ }^{[51]}$ solar cells, ${ }^{[52]}$ self-cleaning, ${ }^{[33]}$ photodetectors, ${ }^{[54]}$ thermoelectric materials ${ }^{[55]}$ and photoelectrochemical ${ }^{[56]}$ applications. Ternary and quaternary metal oxides/sulfides/selenides are ones which contain 2 and 3 different metals, respectively. As there are different metal centres in these compounds, the structural and electronic properties of these materials are often significantly different compared to the binary metal oxide analogues. These materials often display solid-solution behaviour, so the metal concentrations can be altered to tune the properties of the material for a specific application. ${ }^{[57]}$ As such, this makes these a class of materials that being able to synthesise by a variety of different routes would be appealing.

Besides AACVD routes, ternary and quaternary oxides and sulfides have been synthesised by atomic layer deposition, ${ }^{[58]}$ solid state synthesis, ${ }^{[59]}$ molecular beam epitaxy ${ }^{[60]}$ and metalorganic chemical vapour deposition. ${ }^{[61]}$ As with metal oxide, sulfide and composites, the above routes suffer from issues including toxic precursors/byproducts, slow growth rates, high deposition/synthesis temperatures and limited suitable precursors. AACVD routes can address these drawbacks, through careful precursor and experimental design.

Thin films of $A g n_{5} S_{8}$ thin films were deposited from the single molecular precursor, $\left[\left(\mathrm{Ph}_{3} \mathrm{P}\right)_{2}\right.$ $\left.\mathrm{Ag} \operatorname{In}(\mathrm{SC}\{\mathrm{O}\} \mathrm{R})_{4}\right]$ where $\mathrm{R}=\mathrm{Me}$ or $\mathrm{Ph} .{ }^{[62]}$ Thin films of $\mathrm{Ag} \mathrm{In}_{5} \mathrm{~S}_{8}$ could be successfully deposited between 350-450 ${ }^{\circ} \mathrm{C}$, with higher temperatures favouring the formation of ribbon-like morphologies, as shown in Figure 9, and increase in the intensity of lower angle diffraction peaks. 


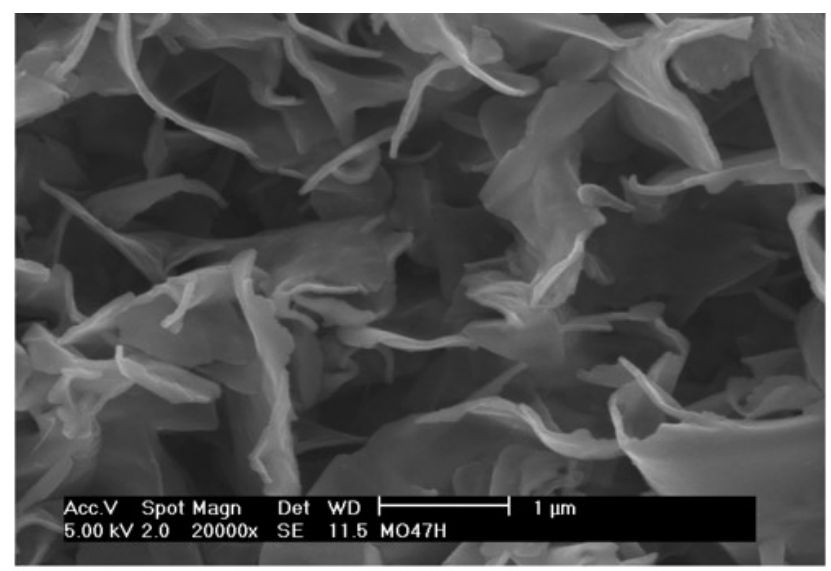

(a)

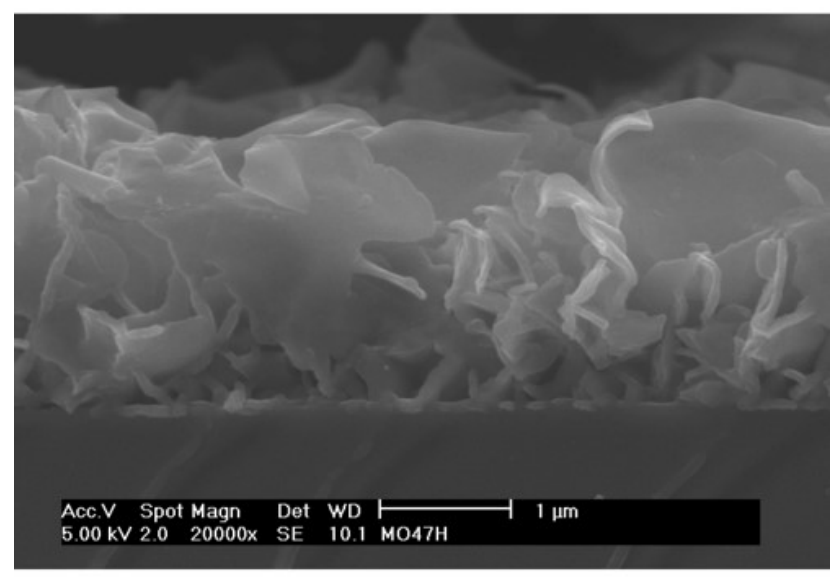

(b)

Figure 9: Surface morphology and side-on SEM images of ribbon-like morphology of $A g \mathrm{n}_{5} \mathrm{~S}_{8}$ thin films deposited by AACVD at $450{ }^{\circ} \mathrm{C}$. Reprinted with permission from Chemistry of Materials. ${ }^{[62]}$ Copyright 2003 American Chemical Society.

A ternary metal oxide, monoclinic $\mathrm{BiVO}_{4}$ has also been deposited via AACVD. ${ }^{[63]}$ This material has been suggested as a good candidate material for photoelectrochemical (PEC) water splitting applications, especially if it can be incorporated into a heterojunction. ${ }^{[64]}$ In the study, monoclinic $\mathrm{BiVO}_{4}$ thin films were deposited on $\mathrm{F}$-doped $\mathrm{SnO}_{2}$ substrates by forming a precursor in solution by the reaction between bismuth nitrate pentahydrate and vanadyl acetylacetonate (acac) in acetylacetonate. The as formed $\mathrm{Bi} / \mathrm{V}$ precursor was then decomposed over the $\mathrm{F}$-doped $\mathrm{SnO}_{2}$ substrate at $500{ }^{\circ} \mathrm{C}$ using compressed air as the carrier gas. The $\mathrm{BiVO}_{4}$ films were found to display PEC water splitting activity, under visible light irradiation, when exposed to AM 1.5 simulated light (this corresponds to the spectrum of sunlight at ground level with an inclined plane at $37^{\circ}$ tilt toward the equator, facing the sun) in a solution of $1.0 \mathrm{M} \mathrm{Na}_{2} \mathrm{SO}_{4}\left(\mathrm{pH} \mathrm{5.70)}\right.$ electrolyte. $\mathrm{BiFeO}_{3}$ has also been successfully deposited via AACVD methods and shown to have excellent PEC properties under UV irradiation $(\lambda=365 \mathrm{~nm}) .{ }^{[65]}$

$\mathrm{Bi}_{2} \mathrm{Ti}_{2} \mathrm{O}_{7}$ thin films have also been deposited by AACVD. ${ }^{[66]}$ In this study, bismuth nitrate pentahydrate (in acetylacetone) and titanium isopropoxide were dissolved in methanol. The deposited thin films were shown to be pure-phase $\mathrm{Bi}_{2} \mathrm{Ti}_{2} \mathrm{O}_{7}$ after the films had been annealed at $600{ }^{\circ} \mathrm{C}$ for 12 hours (in air). The films were shown to have excellent PEC properties for water splitting applications. 
A further ternary metal oxide, $\mathrm{NiTiO}_{3}$, has also been successfully synthesised by using a single-source precursor to deposit thin films via AACVD. ${ }^{[67]}$ The single-source precursor, $\left[\mathrm{Ni}_{2} \mathrm{Ti}_{2}(\mathrm{OEt})_{2}(\mu-\right.$ OEt $\left.)_{6}(\mathrm{acac})_{4}\right]$, was synthesised by the reaction between $\mathrm{Ti}\left(\mathrm{OC}_{2} \mathrm{H}_{5}\right)_{4}$ and $\mathrm{Ni}(\mathrm{acac})_{2}$, which are both readily available precursors. The $\mathrm{NiTiO}_{3}$ thin films showed excellent PEC properties for water splitting applications. The routes outlined above again show how engineering the precursor can lead to both the ease of formation of the desired product and also reduce the environmental impact of synthesising the functional material.

Metal tungstate precursors have also been synthesised and shown to be a route towards metal tungstate thin films. ${ }^{[68]}$ Here the precursors $\left[\mathrm{M}_{2} \mathrm{~W}_{2}(\mathrm{O})_{2}(\mathrm{acac})_{2}(\mathrm{OMe})_{10}\right]$, where $\mathrm{M}=\mathrm{Co}, \mathrm{Ni}, \mathrm{Mg}$ or $\mathrm{Zn}$, were synthesised by reacting [ $\left.\mathrm{Ni}(\mathrm{acac})_{2}\right],\left[\mathrm{Mg}(\mathrm{acac})_{2}\right],\left[\mathrm{Zn}(\mathrm{acac})_{2}\right]$ or [Co(acac)(OMe) ] with [WO $\left.(\mathrm{OMe})_{4}\right]$. Such a synthetic route would eliminate the need to use halogenated precursors and also use readily available and chemically stable precursors with non-toxic byproducts produced.

The above synthetic techniques eliminate the use of precursors containing halides, thus preventing the formation of $\mathrm{HF} / \mathrm{Cl} / \mathrm{Br} / \mathrm{I}$. Also, with temperatures at or below $600{ }^{\circ} \mathrm{C}$, these reactions can be incorporated into float glass production where the as-solidified glass comes off the process line at ca. $600{ }^{\circ} \mathrm{C}$ and is controllably cooled, allowing time for deposition of functional thin films. As the glass has to be formed at elevated temperatures, there is no additional energy requirement for the synthesis of the thin film material deposited onto the glass in this process.

\subsection{Current challenges and future directions of AACVD}

There are several areas where AACVD methods will need to be improved prior to the technology being adopted for industrial coating applications. One of these is the deposition rate since lab based AACVD experiments typically take 30-60 mins to deposit ca. $1000 \mathrm{~nm}$ of material. This is clearly too slow for industrial applications, where the rate is $1000 \mathrm{~s} \mathrm{~nm} \mathrm{~min}^{-1}$. Therefore, increasing the deposition rate whilst being able to maintain the functional properties of the deposited thin films and high sustainability of the process, is a key area that needs to be established. We have been able to show that AACVD can be scaled from $10 \mathrm{~s} \mathrm{~nm} \mathrm{~min}^{-1}$ to $100 \mathrm{~s} \mathrm{~nm} \mathrm{~min}^{-1}$ without loss of functionality. ${ }^{[69]}$ This shows that AACVD is a scalable process. However, additional work is required to get it to rates that are appropriate for industrial applications.

A second area where AACVD methods require further development is on the synthesis of singlesource precursors. As shown in this concept article, single-source precursors are a powerful route to achieving a range of functional materials. These precursors do require additional research, to ensure that the precursors can be easily synthesised from existing chemical feedstocks, and that the decomposition pathways are tailored to ensure that the reliable deposition of the functional materials can occur.

A further area where AACVD methods need greater research focus is on the development of more types of functional thin films including the deposition of multilayered structures and embedding nanoparticles of one material into a 'host' matrix of another material. The latter of these has been demonstrated for the incorporation of noble metals ( $\mathrm{Ag}, \mathrm{Au}$ and $\mathrm{Pt}$ ) into thin films of metal oxides, ${ }^{[47}$, ${ }^{70]}$ however this could be further extended to producing heterojunctions where two or more metal oxide/sulfide/selenide/phosphide/arsenide materials are deposited to engineer the band structures to achieve the desired functional properties. Heterojunctions are being heavily researched for 
advanced functional materials, as the ability to have multiple band structures interacting with each other means that the electronic properties of these materials can be manipulated. ${ }^{[64]}$ This means that combining two or more different materials, and hence different band-structures, can give enhanced properties, such as visible light photocatalysis or high electrical efficiency.

The deposition of multilayered structures should be easily achievable for AACVD routes, multilayers are commonly deposited by other CVD routes by pulsing the metal precursors, so that each layer grows sequentially, building up the material layer-by-layer. ${ }^{[71]}$ Therefore, growing multilayered structures by AACVD methods should be a matter of using the same principle, where each precursor is 'pulsed' to ensure that there are distinct layers within the microstructure of the film.

Another consideration for improving the sustainability of AACVD processes is the solvent used to dissolve the precursors. Ideally, the solvent in all cases will be water as this would eliminate many unwanted waste products. For many precursor systems, this can be achieved by design of the precursors to ensure high solubility in water. Secondly, the aerosol production should also be designed with water based systems in mind to ensure that the aerosol can be delivered into the reactor. For systems where water may be unsuitable, such as metal sulfides, then the solvent should be carefully chosen to ensure elimination of the most harmful byproducts and a reduction in energy requirements.

AACVD techniques have also been used for the deposition of metal phosphides/selenides/arsenides. ${ }^{[6]}$ This is an area that will become increasingly important for the synthesis of advanced functional materials. As outlined in this article, careful consideration of the precursor chemistry will again allow for these materials to be deposited with sustainability built into the process.

An area where AACVD could be superior to other CVD methods is the deposition of nanoparticulate films or nanoparticles embedded within films. This is due to the fact that AACVD relies on solution chemistry, so long as the nanoparticles can be dispersed within a suitable solvent or synthesised in situ in the reactor, there is nothing preventing the nanoparticles being incorporated into the film. This would allow for the deposition of films where the properties can be tailored by the loading of the nanoparticles in the film, as well as the size of the nanoparticles and the materials the nanoparticles are made of. This would allow such films to be made by a process with fast growth rates and control over the thickness, dopants and deposition conditions- making AACVD potentially a very powerful tool for industrial applications.

\section{Conclusions}

AACVD routes are a powerful synthetic technique for synthesising functional materials with high sustainability. This is a scalable process that combines high growth rates with the ability to tailor the precursors to enable materials to be deposited at lower temperatures whilst also eliminating harmful byproducts. With an increasing focus on the sustainability of industrial processes, aerosol routes have an increasingly important role to play in the production of functional materials.

\section{Acknowledgements}

The authors would like to thank the EPSRC for grant EP/L017709. 


\section{References}

[1] G. Hass, M. H. Francombe and R. W. Hoffman, Physics of Thin Films: Advances in Research and Development, Elsevier, 2013, p.

[2] A. D. Franklin, Science 2015, 349, aab2750.

[3] A. Jayal, F. Badurdeen, O. Dillon and I. Jawahir, CIRP Journal of Manufacturing Science and Technology 2010, 2, 144-152.

[4] P. Marchand, I. A. Hassan, I. P. Parkin and C. J. Carmalt, Dalton Transactions 2013, 42, 9406-9422.

[5] W. Kern, Thin film processes II, Academic press, 2012, p.

[6] C. E. Knapp and C. J. Carmalt, Chemical Society Reviews 2016, 45, 1036-1064.

[7] X. Hou and K. L. Choy, Chemical Vapor Deposition 2006, 12, 583-596.

[8] D. S. Bhachu, M. R. Waugh, K. Zeissler, W. R. Branford and I. P. Parkin, Chemistry - A European Journal 2011, 17, 11613-11621.

[9] I. P. Parkin and R. G. Palgrave, Journal of Materials Chemistry 2005, 15, 1689-1695.

[10] C. G. Granqvist, J. Eur. Ceram. Soc. 2005, 25, 2907-2912.

[11] S. C. Dixon, D. O. Scanlon, C. J. Carmalt and I. P. Parkin, Journal of Materials Chemistry C 2016, 4, 6946-6961.

[12] S. PalDey and S. Deevi, Materials Science and Engineering: A 2003, 342, 58-79.

[13] S. Sathasivam, D. S. Bhachu, Y. Lu, N. Chadwick, S. A. Althabaiti, A. O. Alyoubi, S. N. Basahel, C. J. Carmalt and I. P. Parkin, Scientific reports 2015, 5.

[14] A. J. Naik, M. E. Warwick, S. J. Moniz, C. S. Blackman, I. P. Parkin and R. Binions, Journal of Materials Chemistry A 2013, 1, 1827-1833.

[15] C. Piccirillo, R. Binions and I. P. Parkin, Chem. Vap. Deposition 2007, 13, 145-151.

[16] M. R. Waugh, G. Hyett and I. P. Parkin, Chemical Vapor Deposition 2008, 14, 366-372.

[17] A. L. Catherall, M. S. Hill, A. L. Johnson, G. Kociok-Köhn and M. F. Mahon, Journal of Materials Chemistry C 2016, 4, 10731-10739.

[18] L. G. Bloor, J. Manzi, R. Binions, I. P. Parkin, D. Pugh, A. Afonja, C. S. Blackman, S. Sathasivam and C. J. Carmalt, Chemistry of Materials 2012, 24, 2864-2871.

[19] C. E. Knapp, G. Hyett, I. P. Parkin and C. J. Carmalt, Chemistry of Materials 2011, 23, 1719-1726.

[20] R. G. Palgrave and I. P. Parkin, Journal of Materials Chemistry 2004, 14, 2864-2867.

[21] J. Zhang, Q. Zou and H. Tian, Advanced Materials 2013, 25, 378-399.

[22] S. D. Ponja, S. Sathasivam, I. P. Parkin and C. J. Carmalt, Rsc Advances 2014, 4, 49723-49728.

[23] J. A. Manzi, C. E. Knapp, I. P. Parkin and C. J. Carmalt, European Journal of Inorganic Chemistry 2015, 2015, 3658-3665.

[24] B. J. Blackburn, J. H. Crane, C. E. Knapp, M. J. Powell, P. Marchand, D. Pugh, J. C. Bear, I. P. Parkin and C. J. Carmalt, Materials \& Design 2016, 108, 780-790.

[25] R. O. Bonsu, D. C. Bock, H. Kim, R. Y. Korotkov, K. A. Abboud, T. J. Anderson and L. McElweeWhite, Dalton Transactions 2016, 45, 10897-10908.

[26] H. Shin, K. Chi, M. Hampden-Smith, T. Kodas, J. Farr and M. Paffett, Chemistry of Materials 1992, 4, 788-795.

[27] H. Bischoff, M. Berger, B. Keppler and D. Schmähl, Journal of cancer research and clinical oncology 1987, 113, 446-450.

[28] K. D. Pollard and R. J. Puddephatt, Chemistry of Materials 1999, 11, 1069-1074.

[29] S. R. Drake, S. A. Miller, M. B. Hursthouse and K. A. Malik, Polyhedron 1993, 12, 1621-1634.

[30] A. G. Avent, M. R. Crimmin, M. S. Hill and P. B. Hitchcock, Organometallics 2005, 24, 1184-1188.

[31] A. G. Barrett, I. J. Casely, M. R. Crimmin, M. S. Hill, J. R. Lachs, M. F. Mahon and P. A. Procopiou, Inorganic Chemistry 2009, 48, 4445-4453.

[32] R. A. Gardiner, D. C. Gordon, G. T. Stauf, B. A. Vaartstra, R. L. Ostrander and A. L. Rheingold, Chemistry of Materials 1994, 6.

[33] R. G. Gordon, S. Barry, R. N. Broomhall-Dillard and D. J. Teff, Advanced Functional Materials 2000, 10, 201-212.

[34] H. Wang, C. Xia, G. Meng and D. Peng, Materials Letters 2000, 44, 23-28. 
[35] T. Wildsmith, M. S. Hill, A. L. Johnson, A. J. Kingsley and K. C. Molloy, Chemical Communications 2013, 49, 8773-8775.

[36] W. Shockley, Bell Labs Technical Journal 1949, 28, 435-489.

[37] I. Barbul, A. L. Johnson, G. Kociok-Köhn, K. C. Molloy, C. Silvestru and A. L. Sudlow, ChemPlusChem 2013, 78, 866-874.

[38] A. A. Tahir, K. U. Wijayantha, S. Saremi-Yarahmadi, M. Mazhar and V. McKee, Chemistry of Materials 2009, 21, 3763-3772.

[39] C. Edusi, G. Hyett, G. Sankar and I. P. Parkin, Chemical Vapor Deposition 2011, 17, 30-36.

[40] C.-H. Lai, M.-Y. Lu and L.-J. Chen, Journal of Materials Chemistry 2012, 22, 19-30.

[41] G. Hogarth, Progress in Inorganic Chemistry, Volume 53 2005, 71-561.

[42] N. Hollingsworth, A. Roffey, H.-U. Islam, M. Mercy, A. Roldan, W. Bras, M. Wolthers, C. R. A. Catlow, G. Sankar and G. Hogarth, Chemistry of Materials 2014, 26, 6281-6292.

[43] a) S. Mlowe, D. J. Lewis, M. A. Malik, J. Raftery, E. B. Mubofu, P. O'Brien and N. Revaprasadu, Dalton Transactions 2016, 45, 2647-2655; b) S. Saeed, K. S. Ahmed, N. Rashid, M. A. Malik, P. O'Brien, M. Akhtar, R. Hussain and W.-T. Wong, Polyhedron 2015, 85, 267-274; c) S. Mlowe, L. D. Nyamen, P. T. Ndifon, M. A. Malik, J. Raftery, P. O'Brien and N. Revaprasadu, Inorganica Chimica Acta 2015, 434, 181-187.

[44] K. Ramasamy, V. L. Kuznetsov, K. Gopal, M. A. Malik, J. Raftery, P. P. Edwards and P. O'Brien, Chemistry of Materials 2013, 25, 266-276.

[45] D. J. Lewis, A. A. Tedstone, X. L. Zhong, E. A. Lewis, A. Rooney, N. Savjani, J. R. Brent, S. J. Haigh, M. G. Burke and C. A. Muryn, Chemistry of Materials 2015, 27, 1367-1374.

[46] J. Kao, K. Thorkelsson, P. Bai, Z. Zhang, C. Sun and T. Xu, Nature communications 2014, 5.

[47] R. G. Palgrave and I. P. Parkin, Journal of the American Chemical Society 2006, 128, 1587-1597.

[48] U. Qureshi, C. W. Dunnill and I. P. Parkin, Applied Surface Science 2009, 256, 852-856.

[49] M. Shahid, M. Mazhar, M. Hamid, M. Zeller, P. O’Brien, M. A. Malik, J. Raftery and A. D. Hunter, New Journal of Chemistry 2009, 33, 2241-2247.

[50] N. P. Chadwick, E. N. Glover, S. Sathasivam, S. N. Basahel, S. A. Althabaiti, A. O. Alyoubi, I. P. Parkin and C. J. Carmalt, Journal of Materials Chemistry A 2016, 4, 407-415.

[51] M. Reddy, G. Subba Rao and B. Chowdari, Chemical Reviews 2013, 113, 5364-5457.

[52] D. Aldakov, A. Lefrançois and P. Reiss, Journal of Materials Chemistry C 2013, 1, 3756-3776.

[53] M. D. Regulacio and M.-Y. Han, Accounts of Chemical Research 2016, 49, 511-519.

[54] J.-J. Wang, J.-S. Hu, Y.-G. Guo and L.-J. Wan, Journal of Materials Chemistry 2011, 21, 1758217589.

[55] M. L. Liu, I. W. Chen, F. Q. Huang and L. D. Chen, Advanced Materials 2009, 21, 3808-3812.

[56] X. J. Wu, X. Huang, X. Qi, H. Li, B. Li and H. Zhang, Angewandte Chemie International Edition 2014, 53, 8929-8933.

[57] S. Pearton, C. Abernathy, M. Overberg, G. Thaler, D. Norton, N. Theodoropoulou, A. Hebard, Y. Park, F. Ren and J. Kim, Journal of Applied Physics 2003, 93, 1-13.

[58] R. W. Johnson, A. Hultqvist and S. F. Bent, Materials today 2014, 17, 236-246.

[59] A. Prakash, P. Manikandan, K. Ramesha, M. Sathiya, J. Tarascon and A. Shukla, Chemistry of Materials 2010, 22, 2857-2863.

[60] H. Temkin, M. Panish, P. Petroff, R. Hamm, J. Vandenberg and S. Sumski, Applied physics letters 1985, 47, 394-396.

[61] Y. Kim, H. J. Joyce, Q. Gao, H. H. Tan, C. Jagadish, M. Paladugu, J. Zou and A. A. Suvorova, Nano letters 2006, 6, 599-604.

[62] T. C. Deivaraj, J.-H. Park, M. Afzaal, P. O'Brien and J. J. Vittal, Chemistry of Materials 2003, 15, 2383-2391.

[63] P. Brack, J. S. Sagu, T. Peiris, A. McInnes, M. Senili, K. Wijayantha, F. Marken and E. Selli, Chemical Vapor Deposition 2015, 21, 41-45.

[64] S. J. Moniz, S. A. Shevlin, D. J. Martin, Z.-X. Guo and J. Tang, Energy \& Environmental Science 2015, 8, 731-759. 
[65] S. J. Moniz, R. Quesada-Cabrera, C. S. Blackman, J. Tang, P. Southern, P. M. Weaver and C. J. Carmalt, Journal of Materials Chemistry A 2014, 2, 2922-2927.

[66] A. McInnes, J. S. Sagu and K. Wijayantha, Materials Letters 2014, 137, 214-217.

[67] A. A. Tahir, M. Mazhar, M. Hamid, K. U. Wijayantha and K. C. Molloy, Dalton Transactions 2009, 3674-3680.

[68] H. Choujaa, A. L. Johnson, G. Kociok-Köhn and K. C. Molloy, Polyhedron 2013, 59, 85-90.

[69] M. J. Powell, D. B. Potter, R. L. Wilson, J. A. Darr, I. P. Parkin and C. J. Carmalt, Materials \& Design 2017.

[70] a) C. Chew, P. Bishop, C. Salcianu, C. J. Carmalt and I. P. Parkin, Rsc Advances 2014, 4, 1318213190; b) S. Vallejos, P. Umek, T. Stoycheva, F. Annanouch, E. Llobet, X. Correig, P. De Marco, C. Bittencourt and C. Blackman, Advanced Functional Materials 2013, 23, 1313-1322.

[71] M. J. Powell, R. Quesada-Cabrera, A. Taylor, D. Teixeira, I. Papakonstantinou, R. G. Palgrave, G. Sankar and I. P. Parkin, Chemistry of Materials 2016, 28, 1369-1376. 